\title{
Genetics of Brassica rapa (syn. campestris). 2. Multiple disease resistance to three fungal pathogens: Peronospora parasitica, Albugo candida and Leptosphaeria maculans
}

\author{
THOMAS MITCHELL-OLDS* ${ }^{*}$ R. VAUGHN JAMES, $\uparrow$ MARY J. PALMER $\uparrow \&$ PAUL H. \\ WILLIAMS + \\ Division of Biological Sciences, University of Montana, Missoula, MT 59812 and †Department of Plant Pathology, \\ University of Wisconsin, Madison, WI 53706, U.S.A.
}

\begin{abstract}
Although the genetic basis of multiple disease resistance (MDR) is poorly understood, it is of great value for understanding the evolution of disease resistance in natural plant populations and for increasing crop yields in agriculture. In Brassica rapa, we studied genetic correlations among levels of disease resistance to three fungal pathogens: Peronospora parasitica, Albugo candida and Leptosphaeria maculans. A large, replicated quantitative genetics experiment used artificial selection on resistance to individual pathogens, and examined correlated responses to selection for resistance to other, unselected pathogens. Data from 9518 plants, each measured simultaneously for resistance to three fungal pathogens, showed heritable genetic variation for resistance to each pathogen and a positive genetic correlation between resistance to $P$. parasitica and $L$. maculans. This indicates that some resistance genes provide defence against fundamental characteristics common to two taxonomic orders of fungal pathogens. Conceivably, such MDR could contribute to a durable defence that might not be easily circumvented by rapidly evolving fungal pathogens.
\end{abstract}

Keywords: Brassica rapa, fungal pathogens, genetic correlations, multiple disease resistance.

\section{Introduction}

The genetics of host plant resistance to pathogens poses many important questions for plant breeders and geneticists. If levels of resistance to different pathogens are positively correlated, then improvement of resistance will be facilitated in agricultural or natural populations whereas negative correlations among levels of resistance would hinder plant defence against pathogen attack. The genetic basis of multiple disease resistance (MDR) is poorly understood and is complicated by environmental interactions among pathogens and correlated gene expression for different resistance traits. Quantitative genetic analysis (Tepper \& Anderson, 1984; Mitchell-Olds \& Rutledge, 1986; Geiger \& Heun, 1989) can be used simultaneously to address resistance against multiple pathogens and to identify pro-

${ }^{*}$ Correspondence. ductive areas for subsequent application of physiological or molecular analysis.

The techniques of population and quantitative genetics can improve understanding of expression of genes for disease resistance and problems in breeding for MDR. Concepts of pathogen-specific and pathogen-nonspecific resistance are algebraically related to genetic correlations (Mitchell-Olds \& Rutledge, 1986), which predict the correlated response in resistance to one pathogen that occurs when selecting for resistance to another. Plant pathologists have elucidated numerous examples of oligogenic and polygenic resistance to pathogens (Day, 1974). In some cases, there are obvious effects of major genes on disease resistance and breeders employ classical Mendelian techniques. Alternatively, continuous distributions of disease reaction are taken to indicate polygenic resistance caused by many genes of small effect and the techniques of quantitative genetics are utilized (Edwards, 1987). 
However, few studies have analysed pleiotropic effects on MDR. Studies which report on polygenic resistance to several diseases are rare (Elgin et al., 1970; Hill \& Leath, 1975; Nyhus et al., 1989).

In this paper, we report a selection experiment in Brassica rapa L. (syn. B. campestris L.) examining changes in multiple disease resistance. We ask the following questions. (i) Is there response to selection for disease resistance? (ii) Is there correlated response to selection? (iii) Are there phenotypic correlations among levels of resistance to different pathogens? Our results show heritable quantitative variation for resistance to Albugo candida, Peronospora parasitica and Leptosphaeria maculans and a positive genetic correlation between resistance to Peronospora and Leptosphaeria.

\section{Materials and methods}

White rust (Albugo candida Pers ex. Hook., Oomycetes, Albuginaceae) is an obligately biotrophic intercellular parasite that attacks the leaves, stems and flowers of many crucifers. Strain AC-2 of $A$. candida was grown on Brassica juncea (L.) Cosson cultivar Southern Giant Curled Mustard, zoosporangia were collected and stored frozen, and inoculum prepared as described (Williams, 1985). Downy mildew (Peronospora parasitica Pers ex. Fr., Oomycetes, Peronosporaceae) is an obligate biotroph that infects the leaves, stems, roots and flowers of numerous cultivated and wild species of Cruciferae. The downy mildew fungus (strain PP558) was grown on $B$. campestris cultivar Michihili. Maintenance, spore collection and inoculation procedures have been described in Williams (1985). Blackleg disease is caused by Leptosphaeria maculans (Desm.) Ces. \& de Not. (Loculoascomycetes, Pleosporales), a facultatively saprophytic, necrotrophic pathogen attacking many crucifers, especially in the genus Brassica (Gabrielson, 1983). Isolate PHW-100, of pathogenicity group 4 (Koch et al., 1991), was grown on V-8 agar plates under cool-white fluorescent lights at $23^{\circ} \mathrm{C}$. All plant and fungal stocks were obtained from the Crucifer Genetics Cooperative, Madison, WI.

An open-pollinated, genetically polymorphic population of rapid cycling Brassica rapa (Williams, 1985) was used as the host species. Brassica rapa plants were maintained in a growth chamber with constant illumination at a density of 500 plants $\mathrm{m}^{-2}$ in $30 \times 60 \mathrm{~cm}$ plastic flats filled with commercial potting soil (Jiffy mix). Seedlings were maintained at $24^{\circ} \mathrm{C}$ and 90 per cent relative humidity, with continuous illumination at a photon flux density of 250 $\mu \mathrm{E} \mathrm{m}^{-2} \mathrm{~s}^{-1}$ from Sylvania cool-white fluorescent bulbs. Five days after sowing, seedlings were wounded in the centre of one cotyledon by puncturing with forceps, and inoculated with a $10 \mu \mathrm{L}$ droplet of distilled water containing $1.0 \times 10^{7} \mathrm{~L}$. maculans pycnidiospores $\mathrm{mL}^{-1}$, which was placed on the wound site. One day later, the opposite cotyledon was inoculated with $10 \mu \mathrm{L}$ each of $A$. candida and $P$. parasitica $\left(1.0 \times 10^{5}\right.$ and $1.0 \times 10^{4}$ spores $\mathrm{mL}^{-1}$, respectively). The inoculum was placed in opposite corners of the cotyledon without wounding, flats were placed in a dew chamber at $20^{\circ} \mathrm{C}$ and 100 per cent relative humidity for $24 \mathrm{~h}$, then returned to the growth chamber. Each flat contained highly susceptible positive control plants to verify successful infection by each pathogen (Brassica oleracea cultivar Jersey Queen, $B$. rapa cultivar Michihili and $B$. juncea cultivar Southern Giant Curled Mustard for $L$. maculans, $P$. parasitica and $A$. candida, respectively). Although this study considered only one isolate of each pathogen species, we nevertheless examined almost 10,000 plants, each assayed for resistance to three pathogens. It was experimentally infeasible to include additional isolates of each fungal pathogen.

Seven (Peronospora), 8 (Albugo) or 9 (Leptosphaeria) days after inoculation, disease severity was scored on a zero to nine scale based on Williams (1985), with zero indicating no disease symptoms and nine indicating severe disease.

The experimental design consisted of three selection treatments and a randomly selected control, each replicated three times. Each generation of each replicate contained 200 plants scored for severity of each fungal disease. In each generation we chose the 20 plants that were most resistant in each replicate, and mass-pollinated these to produce the next generation. In contrast, 20 randomly selected plants were chosen from the randomly selected control lines to propagate the next generation. In the next generation 10 progeny were planted from each maternal plant (Fig. 1) in randomized positions. Each treatment or control replicate was subject to three cycles of selection and measured for four generations, providing a total of 12 independent replicate lines (Fig. 2). Sample sizes were occasionally lower than planned as a result of reduced germination or accidents to individual plants. In total, 28,554 measurements of disease severity were obtained on 9518 plants, each assayed for resistance to three fungal pathogens.

Analysis of changes in disease reaction employed ANCovA (Milliken \& Johnson, 1983; Shaw \& Mitchell-Olds, 1993) on means of about 200 plants from each treatment-replicate-generation population (4 


\section{Generation 1}

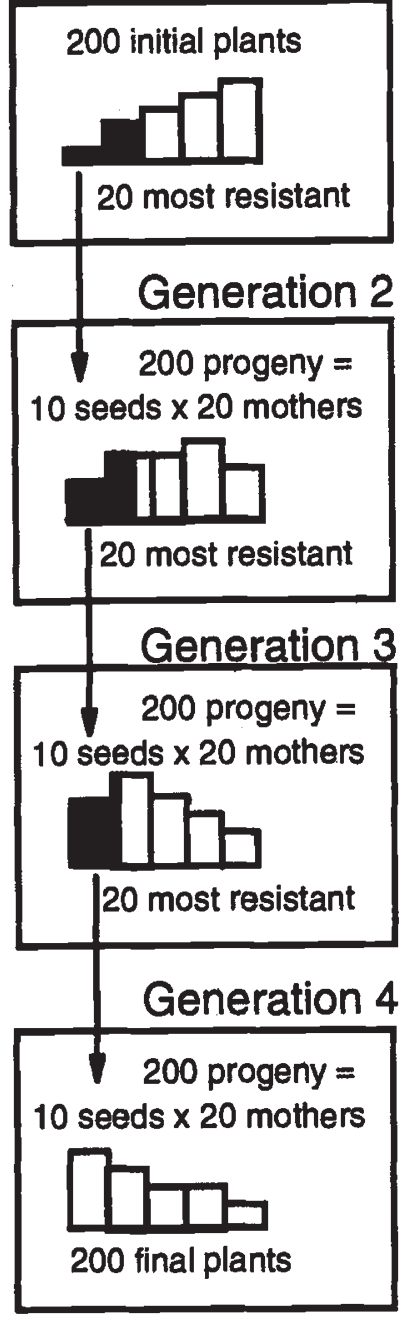

Fig. 1 Selection protocol for each replicate. Disease severity was scored on 200 Brassica rapa plants in generation one. For a particular pathogen, the 20 most resistant plants were chosen as parents for the next generation (black shading; not to scale). Each parent provided 10 seed, which constituted the next generation (200 total). From these plants, the 20 most resistant plants were chosen as parents of the next generation, etc. Three cycles of selection resulted in four generations of data and the level of susceptibility decreased during selection. Data from only one fungal disease were used for selecting parents; information on resistance to the other two pathogens was recorded but not used in the selection scheme. In the randomly selected control treatment, 20 plants were randomly chosen as parents for the next generation. In total, this figure summarizes 28554 measurements of disease severity.

treatments $\times 3$ replicates $\times 4$ generations $=48$ population means). We analysed unweighted population means as estimation error within replicates was less than the variation among replicates attributable to

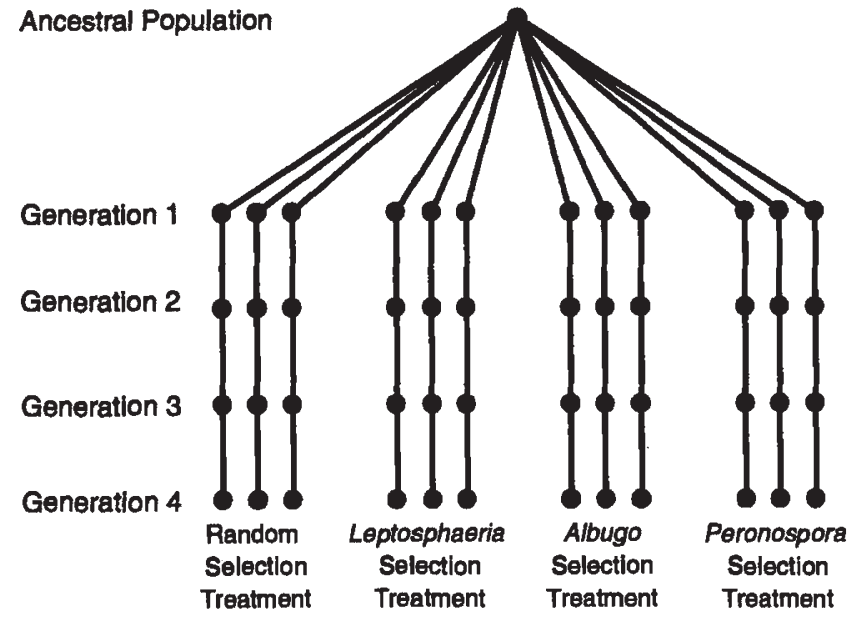

Fig. 2 Pedigree for four selection treatments, each replicated three times. These 12 independent lines were each measured for four generations. The ancestral population was a large, mass-pollinated seed increase derived from rapid cycling Brassica rapa.

genetic drift, environmental differences among months, pathogen preparations, etc. Population replicate was considered to be a random effect, and selection was a fixed effect entered as a 1 d.f. covariate for the linear effects of generations 1-4. Residuals were checked for violation of distributional assumptions. If the linear ANCOVA model was inappropriate, we modelled a curvilinear selection response by quadratic effects of generation or used ANCOVA with delete-one jackknife tests of significance for linear generation effects (Mitchell-Olds, 1986). This procedure is robust to violation of parametric assumptions regarding residuals (Wu, 1986).

\section{Results}

There was a slight increase in susceptibility to Albugo in the random selected control treatment $\left(F_{116}=10.24, P=0.019\right.$; Fig. 3$)$, perhaps because of inbreeding depression in the randomly selected bottleneck populations. Resistance to Leptosphaeria and Peronospora did not change in the controls ( $P>0.3$, not shown).

Selection for resistance to a particular pathogen resulted in rapid evolutionary change (Tables 1 and 2; Figs 3 and 4). Three generations of selection decreased susceptibility to the selected species by $0.98-2.83$ standard deviations. In percentage terms, the initial level of mean susceptibility was reduced by 25 per cent (Albugo, $P=0.009$ ), 63 per cent (Peronospora, $P=0.002$ ) and 70 per cent (Leptosphaeria, $P=0.001)$. Within a selection treatment, replicate 
Fig. 3 Changes in disease severity showing direct and correlated responses to selection. Each column shows a selection or control treatment. Column 1, randomly selected control: a-c. Column 2, selection on Leptosphaeria: d-f. Column 3, selection on Albugo: $\mathrm{g}-\mathrm{i}$. Column 4, selection on Peronospora: jl. Response for a given pathogen is shown in rows. Row 1, Leptosphaeria: a, d, g, j. Row 2, Albugo: b, e, h, k. Row 3, Peronospora, c, f, i, l. Error bars show the standard error of replicate means. Each figure shows four generations and each point indicates the grand mean of three replicates. Thus, each point represents measurements on about 600 Brassica rapa plants.

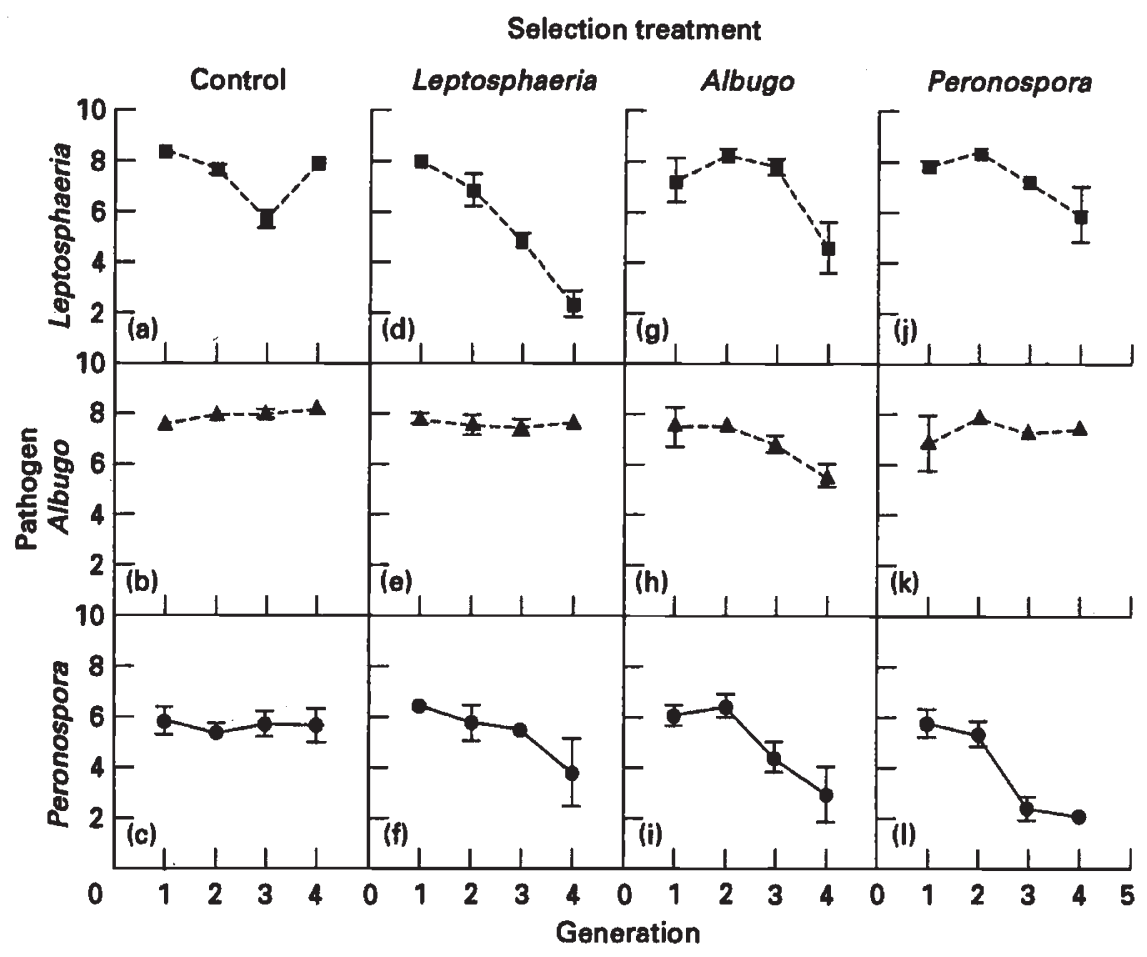

Table 1 Changes in mean disease severity

\begin{tabular}{lcrr}
\hline Response & Leptosphaeria & Albugo & Peronospora \\
\hline Selection on Leptosphaeria & & & \\
Generation 1 & 8.11 & 7.92 & 6.50 \\
Generation 4 & 2.42 & 7.75 & 3.82 \\
Change (SD) & -2.83 & -0.12 & -0.97 \\
Selection on Albugo & & & \\
Generation 1 & 7.43 & 7.64 & 6.11 \\
Generation 4 & 4.67 & 5.72 & 3.04 \\
Change (SD) & -1.06 & -0.98 & -1.07 \\
Selection on Peronospora & & & \\
Generation 1 & 7.96 & 6.97 & 5.82 \\
Generation 4 & 6.04 & 7.55 & 2.15 \\
Change (SD) & -0.89 & 0.23 & -1.22 \\
\hline
\end{tabular}

Changes in mean disease severity as a result of selection and correlated response to selection. Change (SD) indicates the change in disease susceptibility measured in within-population standard deviation units. lines varied as a result of the effects of genetic drift and environmental variation from month-to-month. However, replicates responded uniformly to a given selection treatment (all replicate $\times$ generation effects were not significantly different from zero). These results demonstrate the existence of significant heritable variation for resistance to each fungal pathogen.

Correlated responses to selection were smaller, but also brought reduced susceptibility to unselected pathogens, primarily with the Leptosphaeria and Peronospora pathogen-pair (Tables 1 and 2; Fig. 3). Correlated declines in susceptibility between Peronospora and Leptosphaeria averaged 33 per cent (Table 1) and were significant in both directions (Table 2). Albugo did not show correlated response to selection on the other pathogens. In the Albugo selection treatment, mean changes in Leptosphaeria resistance were affected by two aberrant replicates in generations 1 and 4 with unusually low levels of disease. 
Table $2 \mathrm{~F}$-ratios showing changes in population mean disease resistance for three pathogens from three selection treatments

\begin{tabular}{lcccc}
\hline Source & d.f. & LM & AC & PP \\
\hline $\begin{array}{l}\text { Leptosphaeria selection experiment } \\
\text { Generation }\end{array}$ & 1 & $62.962^{* * *}$ & 0.603 & $5.448^{*,+}$ \\
Replicate & 2 & 0.267 & 3.589 & 0.374 \\
Rep $\times$ Gen & 2 & 0.367 & 1.694 & 1.760 \\
$\mathrm{R}^{2}$ & & 0.91 & 0.70 & 0.74 \\
Albugo selection experiment & & & & \\
Generation & 1 & 4.037 & $14.486^{* *}$ & $24.914^{* *}$ \\
Replicate & 2 & 1.125 & 2.999 & 0.070 \\
Rep $\times$ Gen & 2 & 1.117 & 3.856 & 1.272 \\
$\mathrm{R}^{2}$ & & 0.55 & 0.80 & 0.88 \\
Peronospora selection experiment & & & & \\
Generation & 1 & $5.411^{*, *}$ & 0.460 & $25.177^{* *}$ \\
Replicate & 2 & 0.331 & 4.863 & 0.725 \\
Rep $\times$ Gen & 2 & 0.976 & 2.983 & 0.522 \\
$\mathrm{R}^{2}$ & & 0.61 & 0.65 & 0.82 \\
\hline
\end{tabular}

LM, AC and PP refer to L. maculans, $A$. candida and P. parasitica, respectively. $\dagger$ Eleven d.f. jackknife $t$-test, $t=2.334, P=0.019$, equivalent to $F_{1,11}=5.448$. $\ddagger$ Two d.f. general linear hypothesis test for second order polynomial on generation.

${ }^{*} P \leqslant 0.05,{ }^{* *} P \leqslant 0.01,{ }^{* * *} P \leqslant 0.001$.

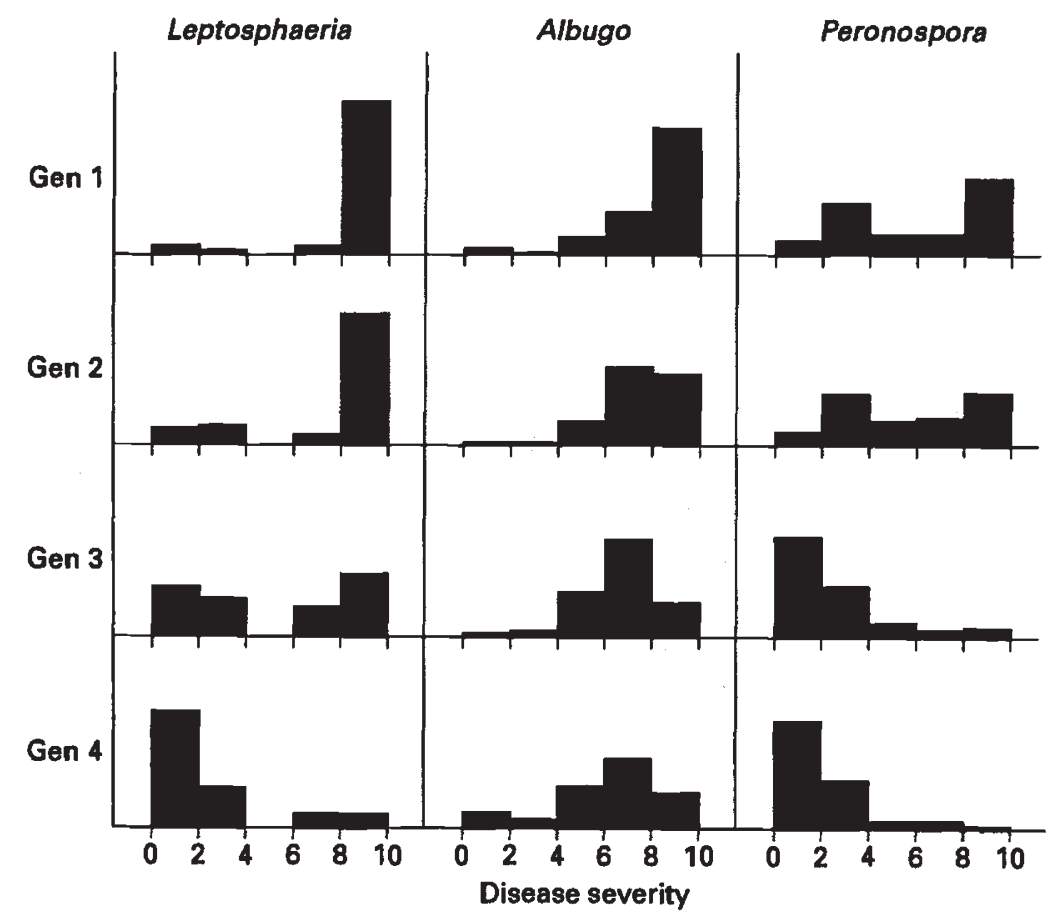

Fig. 4 Histograms showing changes in the distribution of disease severity in three selection treatments (columns) over four generations (rows). Each cell shows pooled disease data from three replicate populations with about 600 Brassica rapa plants per cell.
Overall, there was little evidence for correlated changes in Leptosphaeria resistance following selection on Albugo resistance (Table 2). Finally, resistance to Peronospora declined significantly in the Albugo selection experiment. These results demon- strate a significant positive genetic correlation among levels of resistance to Leptosphaeria and Peronospora and perhaps between Albugo and Peronospora.

The positive genetic correlations among levels of

(C) The Genetical Society of Great Britain, Heredity, 75, 362-369. 
Table 3 Correlations among levels of disease resistance

\begin{tabular}{lccc}
\hline & Peronospora & Albugo & Leptosphaeria \\
\hline Peronospora & 1.0000 & & \\
Albugo & 0.1129 & 1.0000 & \\
Leptosphaeria & 0.0832 & 0.0830 & 1.0000 \\
\hline
\end{tabular}

Phenotypic correlations among disease scores in generation 1 . $N=2,479$. All $P<0.001$ by jackknife $t$-test (Mitchell-Olds, 1986; Wu, 1986).

disease resistance were also paralleled by positive phenotypic correlations at the level of individual plants (Table 3). Correlations were calculated in generation 1 within each replicate (three selection treatments and one control, each with three replicates) and then pooled. Pooling was appropriate as all plants were random members of the original base population, measured before different selection treatments had begun. Small positive phenotypic correlations ranged between 0.08 and 0.11 , but were found to be statistically significant because of the large sample size.

\section{Discussion}

We examined multiple disease resistance in 9,518 plants, each measured simultaneously for resistance to three fungal pathogens. In each treatment we selected for greater resistance to a single pathogen species. In several instances we observed correlated responses for resistance to other pathogen species, although no selection was directed at these other species. Such positive correlated responses are the result of positive genetic correlations (Lande \& Arnold, 1983), which indicate a positive association at the level of genotypes or breeding values (Falconer, 1989).

We found strong evidence for a positive genetic correlation in levels of resistance to Leptosphaeria and Peronospora, an Ascomycete and an Oomycete, respectively. This genetic correlation may indicate the presence of plant resistance genes that provide defence against some fundamental characteristic common to two taxonomic orders of fungal pathogens (Bruns et al., 1991). Conceivably, such multiple disease resistance could contribute to a durable defence that might not be easily circumvented by rapidly evolving fungal pathogens.

Genetic correlations can arise from several factors. (i) Linkage disequilibrium, a nonrandom association among genotypes at several loci, is rarely found in outbred species (Crow \& Kimura, 1970) such as $B$. rapa. However, linkage disequilibrium can arise from previous generations of selection or small population size (Crow \& Kimura, 1970), as occurred in the rapid cycling populations of $B$. rapa prior to the onset of this experiment. (ii) Pleiotropy, the influence of a particular locus on several traits, is usually thought to be the cause of genetic correlations in outbred populations (Crow \& Kimura, 1970). This suggests that the positively correlated changes in MDR observed in this experiment are caused by loci that simultaneously cause resistance to several unrelated species of fungal pathogen. Finally, (iii) tight linkage between resistance genes (Martin et al., 1993) can also cause genetic correlations or correlated responses to selection. Experiments for molecular mapping of quantitative trait loci can begin to distinguish between linkage disequilibrium and pleiotropy as causes of the observed genetic correlations (Lander \& Botstein, 1989).

Analysis of polygenic MDR applies the standard, well documented techniques of quantitative genetics (Kempthorne, 1957; Lin, 1978; Hallauer \& Miranda, 1981; Falconer, 1989) to polygenic disease resistance. Heritabilities measure the proportion of the total phenotypic variation that is available for selection and genetic correlations quantify the amount of 'genetic connection' between levels of resistance to two different pathogens. These genetic parameters permit multiple trait selection for increased resistance to several diseases (Hazel, 1943; Hallauer \& Miranda, 1981; Lande \& Arnold, 1983; Falconer, 1989). In the present study, positive genetic correlations indicate that selection for resistance to a single pathogen will also bring increasing resistance to other species. Indeed, the theory of selection indices may be applied to simultaneous selection for MDR (Hazel, 1943; Lin, 1978; Falconer, 1989). By accounting for multivariate patterns of disease resistance, gains in resistance to an economically important pathogen can proceed more rapidly than would be possible with single trait selection. This occurs because information on a genetically correlated trait (e.g. Peronospora resistance) provides partial information on the breeding values of the original trait (e.g. Leptosphaeria resistance). Alternatively, combined studies of MDR and agronomic traits such as yield may be able to increase MDR without decreasing other traits of agronomic value.

Possible pleiotropic effects of disease and insect resistance loci have been examined in several previous studies. Nyhus (1989) selected for resistance to Diplodia maydis and first generation European corn 
borer (Ostrinia nubilalis) and found correlated increases in resistance to Colletotrichum graminicola and northern corn leaf blight (caused by Exserohilum turcicum), indicating positive genetic correlations in levels of resistance. Klenke et al. (1987) found evidence for a negative correlation between levels of resistance to an insect and a pathogen, with increasing resistance to European corn borer being associated with decreasing resistance to $E$. turcicum. However, no association was found between levels of resistance to European corn borer and northern corn leaf blight in a very large study by Guthrie (1985). Pataky (1988) found significant positive correlations among mean levels of resistance to several pathogenic microorganisms in a study of sweet corn genotypes. Lambert \& Kilen (1984) found positive associations between levels of resistance to four insect pests in soybean genotypes. Scott et al. (1982) analysed association of agronomic characters in wheat with resistance to Septoria nodorum through three generations of segregation and found a persistent correlation between height and resistance. This association may indicate a causal (pleiotropic) relationship where canopy height influences microclimate and therefore disease susceptibility.

In these experiments, levels of disease caused by Leptosphaeria, Albugo and Peronospora showed a continuous gradation from extremely resistant to extremely susceptible. However, intermediate levels of Leptosphaeria resistance were uncommon, resulting in a bimodal distribution of disease levels (Fig. 4). In other populations of $B$. rapa, resistance to Leptosphaeria is continuously and unimodally distributed (T. Mitchell-Olds, unpublished data). These visual disease resistance scores define a continuous (rather than categorical) scale of measurement which assays visible symptoms of the disease interaction. Similar numerical indicators for underlying variables are commonly used in the path analysis and structural equation modelling literature (Duncan, 1975; Li, 1975). Our findings demonstrate that assays of disease severity defined in this fashion are repeatable, heritable and allow prediction and manipulation of plant disease. We have also found (T. Mitchell-Olds, unpublished data) that visual estimates of disease severity show significant genetic correlations with physiological measurements of putative plant defence pathways.

Studies of genetic differences in resistance to two isolates of $L$. maculans also show continuous variation. In a world-wide collection of $B$. rapa genotypes, Mitchell-Olds and Christian (unpublished data) found continuously distributed variation in blackleg resistance, with a positive correlation of 0.55 among levels of blackleg disease caused by $L$. maculans isolates from pathogenicity groups 3 and 4 (Koch et al., 1991). No plant genotypes were completely susceptible or completely resistant to either pathotype.

It is important to note that methods for identification of multiple loci influencing disease resistance are facilitated by quantitative assays of varying levels of disease resistance. Several studies have shown that the power of statistical tests for the genetic basis of a trait is far greater when resistance is scored as a continuous variable (e.g. our 0-9 scale; Fox \& Williams, 1984; Edwards, 1987;) rather than simply categorized as 'resistant' or 'susceptible' (Morton, 1982). The rapid genetic changes in susceptibility in our studies demonstrate that our visual assays of individual disease resistance provide an effective and repeatable method for quantifying and manipulating plant-pathogen interactions on large numbers of individuals.

Mechanisms of disease resistance in this study are unclear. There was no evidence for a hypersensitive response (Dixon \& Lamb, 1990), where resistance is characterized by rapid, local cell death. For example, plants that were extremely resistant to Leptosphaeria showed symptoms indistinguishable from sterile water mock-inoculated controls. Although the possible importance of induced resistance is unknown in this system, it cannot explain the direct and correlated genetic changes in disease resistance found here (Fig. 3) as multiple pathogen inoculation protocols were identical in each treatment and generation. Quantitative genetic analyses of defensive physiology offer some clues to mechanisms of disease resistance in these populations. For example, the Leptosphaeria resistant populations show significant genetic increases in enzyme activities of chitinase and the shikimic acid pathway (T. MitchellOlds, unpublished data). The disease interaction between Brassica and its fungal pathogens provides an ideal opportunity for simultaneous analyses of polygenic resistance, quantitative genetics of defensive physiology, and QTL mapping of candidate genes.

\section{Acknowledgements}

This research was supported by USDA Competitive Grants SEA-86-CRCR-1-2009 to P.H.W. and T.M.-O. and grants 88-7151-3958 and 92-37303-7613 to T.M.-O.

\section{References}

BRUNS, T. D., White, T. J. AND TAYLOR, J. W. 1991. Fungal molecular systematics. Ann. Rev. Ecol. Syst., 22,

(C) The Genetical Society of Great Britain, Heredity, 75, 362-369. 
525-564.

CROW, J. F. AND KIMURA, M. 1970. An Introduction to Population Genetics Theory. Harper \& Row, New York.

DAY, P. R. 1974. Genetics of Host-Parasite Interaction. Freeman, San Francisco.

DIXON, R. A. AND LAMB, C. J. 1990. Molecular communication in interactions between plants and microbial pathogens. Ann. Rev. Pl. Physiol. Pl. Mol. Biol., 41, 339-367.

DUNCAN, O. D. 1975. Introduction to Structural Equation Models. Academic Press, New York.

EDWARDS, M. D. 1987. Selection of minor gene resistance to Albugo candida in a rapid cycling population of Brassica campestris. Phytopatholgy, 77, 527-532.

ELGIN, J. H., HILL, R. R. JR AND ZEIDERS, K. E. 1970. Comparison of four methods of multiple trait selection for five traits in alfalfa. Crop Sci., 10, 190-193.

FALCONER, D. s. 1989. Introduction to Quantitative Genetics, 3rd edn. Longman, New York.

FOX, D. T. AND Williams, P. H. 1984. Correlation of spore production by Albugo candida on Brassica campestris and a visual white rust rating scale. Can. J. Plant. Pathol., 6, 175-178.

GABRIELSON, R. L. 1983. Blackleg disease of crucifers caused by Leptosphaeria maculans (Phoma lingham) and its control. Seed Sci. Technol., 11, 749-780.

GEIGER, H. H. AND HEUN, M. 1989. Genetics of quantitative resistance to fungal disease. Ann. Rev. Phytopathol., 27, 317-341.

GUTHRIE, W. D., BARRY, B. D., ROSSMAN, E. C. AND JARVIS, J. L. 1985. Correlation between leaf-feeding resistance to European corn borer (Lepidoptera: Pyralidae) and resistance to northern corn leaf blight. J. Econ. Entomol., 78, 811-814.

HALlaUER, A. R. AND MIRANDA, J. B., Fo. 1981. Quantitative Genetics in Maize Breeding. Iowa State University Press, Ames, IA.

HAZEL, L. N. 1943. The genetic basis for constructing selection indices. Genetics, 28, 476-490.

HILL, A. L., JR AND LEATH, K. T. 1975. Genotypic and phenotypic correlations for reaction to five foliar pathogens in alfalfa. Theor. Appl. Genet., 45, 254-258.

KEMPTHORnE, o. 1957. An Introduction to Genetics Statistics. Iowa State University Press, Ames, IA.

KLENKE, J. R., RUSSELL, W. A., GUTHRIE, W. D., MARTINSON, C. A. AND PEDERSEN, W. L. 1987. Disease resistance in five cycles of selection of 'B59' corn synthetic selected for resistance to two generations of European corn borer. Phytopathology, 77, 735-739.

KOCH, E., SONG, K., OSBORN, T. C. AND WILliAMS, P. H. 1991. Relationship between pathogenicity and phylogeny based on restriction fragment length polymorphism in Leptosphaeria maculans. Molec. Plant Microbe Interact., 4, 341-349.
LAMBERT, L. AND KILEN, T. c. 1984. Multiple insect resistance in several soybean genotypes. Crop Sci., 24, $887-890$.

LANDE, R. AND ARNOLD, s. J. 1983. The measurement of selection on correlated characters. Evolution, 37, $1210-1227$.

LANDER, E. S. AND BotsteIN, D. 1989. Mapping Mendelian factors underlying quantitative traits using RFLP linkage maps. Genetics, 121, 185-199.

LI, C. C. 1975. Path Análysis: A Primer. Boxwood Press, Pacific Grove, CA.

L1N, C. Y. 1978. Index selection for genetic improvement of quantitative characters. Theor. Appl. Genet., 52, 49-56.

MARTIN, G. B., BROMMONSCHENKEL, S. H., CHUNWONGSE, J., FRARY, A., GANAL, M. W., SPIVEY, R., WU, T., SEARLE, E. D. AND TANKSLEY, S. D. 1993. Map-based cloning of a protein kinase gene conferring disease resistance in tomato. Science, 262, 1432-1436.

Milliken, G. A. AND Johnson, D. E. 1983. Analysis of Messy Data, vol 1, Designed Experiments. Wadsworth, London.

MITCHELL-OLDS, T. 1986. Discussion of C. F. J. Wu's 'Jackknife, bootstrap and other resampling methods in regression analysis'. Ann. Stat., 14, 1316-1318.

MITCHELL-OLDS, T. AND RUTLEDGE, J. J. 1986. Quantitative genetics in natural plant populations: a review of the theory. Am. Nat., 127, 379-402.

MORTON, N. E. 1982. Outline of Genetic Epidemiology. Karger, NY.

NYHUS, K. A., RUSSEL, W. A., GUTHRIE, W. D. AND MARTINson, C. A. 1989. Reaction of two maize synthetics to anthracnose stalk rot and northern corn leaf blight following recurrent selection for resistance to Diplodia stalk rot and European corn borer. Phytopathology, 79, 166-169.

PATAKY, J. K., HEADRICK, J. M. AND SUPARNYONO. 1988. Classification of sweet corn hybrid reactions to common rust, northern leaf blight, Stewart's wilt and Goss' wilt, and associated yield reduction. Phytopathology, 78, 172-178.

SCOTT, P. R., BENEDIKZ, P. W. AND COX, C. J. 1982. A genetic study of the relationship between height, time of ear emergence and resistance to Septoria nodorum in wheat. Pl. Pathol., 31, 45-60.

SHAW, R. G. AND MITCHELL-OLDS, T. 1993. ANOVA for unbalanced data: an overview. Ecology, 74, 1638-1645.

TEPPER, C. C. AND ANDERSON, A. J. 1984. The genetic basis of plant-pathogen interaction. Phytopathology, 74, 1143-1145.

williams, P. H. 1985. Crucifer Genetics Cooperative Resource Book. University of Wisconsin, Madison, WI.

wu, C. F. J. 1986. Jackknife, bootstrap and other resampling methods in regression analysis. Ann. Statis., 14, 1261-1295. 